\title{
Effect of Bivalent Vaccines against Vibrio anguillarum and Aeromonas salmonicida Subspecie achromogenes on Health and Survival of Turbot
}

\author{
Yolanda Torres-Corral ${ }^{1, *(\mathbb{D})}$, Albert Girons ${ }^{2}$, Oscar González-Barreiro ${ }^{3}$, Rafael Seoane ${ }^{4}(\mathbb{D})$, Ana Riaza ${ }^{3}$ and \\ Ysabel Santos 1 ,* \\ 1 Departamento de Microbiología y Parasitología, Instituto de Análisis Químico y Biológico (IAQBUS), \\ Universidade de Santiago de Compostela, 15782 Santiago de Compostela, Spain \\ 2 Ictiovet S.L., 08025 Barcelona, Spain; albert.girons@ictiovet.com \\ 3 Stolt Sea Farm, Edificio Quercus, 15707 Santiago de Compostela, Spain; o.gonzalez@stolt.com (O.G.-B.); \\ a.riaza@stolt.com (A.R.) \\ 4 Departamento de Microbiología y Parasitología, Facultad de Medicina y Odontología, Universidade de \\ Santiago de Compostela, 15782 Santiago de Compostela, Spain; rafael.seoane@usc.es \\ * Correspondence: yolanda.torres.corral@gmail.com (Y.T.-C.); ysabel.santos@usc.es (Y.S.)
}

check for

updates

Citation: Torres-Corral, Y.; Girons, A.; González-Barreiro, O.; Seoane, R.; Riaza, A.; Santos, Y. Effect of Bivalent Vaccines against Vibrio anguillarum and Aeromonas salmonicida Subspecie achromogenes on Health and Survival of Turbot. Vaccines 2021, 9, 906. https://doi.org/10.3390/ vaccines 9080906

Academic Editors: Beatriz Novoa and Patricia Pereiro

Received: 2 July 2021

Accepted: 11 August 2021

Published: 14 August 2021

Publisher's Note: MDPI stays neutral with regard to jurisdictional claims in published maps and institutional affiliations.

Copyright: (c) 2021 by the authors. Licensee MDPI, Basel, Switzerland. This article is an open access article distributed under the terms and conditions of the Creative Commons Attribution (CC BY) license (https:/ / creativecommons.org/licenses/by/ $4.0 /)$.

\begin{abstract}
The efficacy of intraperitoneal injection of an oil-based bivalent autogenous vaccine and the commercial vaccine AlphaJect 3000 (Pharmaq AS) to prevent atypical furunculosis and vibriosis in turbot was analyzed. The effect of both vaccines on health parameters and survival of fish after challenge with $V$. anguillarum and $A$. salmonicida subsp. achromogenes was tested. The autogenous vaccine conferred high levels of protection and long-lasting immunity against both pathogens with a single dose. However, severe side effects were observed in turbot injected with this autovaccine and minor negative effects with the AlphaJect 3000 vaccine and the adjuvant Montanide or Eolane. All vaccinated fish showed remarkable antibody agglutination titers, higher than those of control fish, which were maintained $160 \mathrm{~d}$ after vaccination. In conclusion, the autogenous bivalent vaccine induces long-lasting protection against atypical furunculosis and vibriosis in turbot, after administration of a single dose, at the cost of high side effects in fish. Therefore, the development of new vaccines should focus on autovaccines and the use of liquid paraffin adjuvants that increase protection with reduced or no side effects.
\end{abstract}

Keywords: atypical furunculosis; vibriosis; autogenous vaccine; turbot; adjuvants

\section{Introduction}

The culture of turbot, Scophthalmus maximus (L.), in aquaculture started in the 1970s in Scotland (UK). Since then, turbot has become one of the main species farmed in Galicia (Spain) and Portugal, in small quantities in other European countries such as France, Norway, Denmark, Holland, and intensively produced in China. Turbot is mainly cultivated in land-based farms with sea water in open flow or using a recirculation aquaculture system (RAS) at temperatures between $12{ }^{\circ} \mathrm{C}$ to $20^{\circ} \mathrm{C}$ [1]. Several bacterial diseases have been a limiting factor in turbot culture, including infections caused by the devastating fish pathogens Aeromonas salmonicida and Vibrio anguillarum [2]. Both bacteria are responsible for hemorrhagic diseases with almost identical clinical signs, such as general hemorrhagic septicemia, external lesions, hemorrhage on the fins, and bloody discharges from the vent $[2,3]$.

Furunculosis in fish is a globally distributed bacterial infection caused by Aeromonas salmonicida. For years, this disease was thought to have a predilection for salmonids. However, over the years, the apparent host range of the pathogen has expanded considerably, being isolated from a wide variety of diseased fish $[2,4]$. Four subspecies of $A$. salmonicida have been isolated from fish with furunculosis, such as A. salmonicida subsp. salmonicida, 
A. salmonicida subsp. masoucida, and A. salmonicida subsp. achromogenes and A. salmonicida subsp. smithia [5]. A. salmonicida subsp. salmonicida is the main causative agent furunculosis, also called "typical furunculosis". The other subspecies are referred to as "atypical strains" which produce "atypical furunculosis" [5,6]. The clinical signs of typical and atypical furunculosis are indistinguishable [2].

Vibriosis in aquaculture is a bacterial disease caused by different species of the genus Vibrio, Listonella, and Aliivibrio [4,6]. The main pathogen causing epizootics in all marine fish species is Vibrio anguillarum. This bacterium is widely distributed throughout the world and affects a huge variety of wild and farmed fish species, resulting in high economic losses in the aquaculture sector [2]. Although a total of 23 serotypes of this species have been described, most of the isolates involved in mortalities in Europe, the USA, and Japan belong to the serotypes $\mathrm{O} 1$ and $\mathrm{O} 2$ (subgroups $\mathrm{O} 2 \alpha$ and $\mathrm{O} 2 \beta$ ) $[2,4,6,7]$.

Traditionally, bacterial threats to aquaculture have been addressed using antimicrobials, including chemotherapeutics, disinfectants, antibiotics, and vaccines. However, the use and misuse of antimicrobials can lead to a rapid increase in the frequency of bacterial resistance, which has a negative impact on the effectiveness of these agents in controlling infectious diseases in aquaculture, the possible transfer of resistance genes from bacteria in the aquatic environment to other bacteria and the possibility of resistance spreading to human pathogens. Careless use of antimicrobials in aquaculture also leads to the possible accumulation of residues in aquaculture products. Consequently, current legislation on the use of antimicrobials in aquaculture has been tightened [8]. The development of infectious disease prevention measures using vaccines is, therefore, a desirable alternative in modern aquaculture. Successful vaccination requires both the development of effective products and their correct use. Numerous vaccine formulations for the control of furunculosis [2,9-11] and vibriosis [2,9,12-16] in fish have been developed. In recent years most vaccine development programs have concentrated on multivalent products [10,17-19] and adjuvants [20] have become important tools for increasing vaccine potency. In fact, most of the vaccines commercially available are polyvalent oil-adjuvanted vaccines. However, difficulties to achieve effective prophylaxis using these vaccines, coupled with the lack of availability and access to authorized vaccines and the legal restrictions on their use in fish species other than licensed species in the EU, has increased the interest in the development and application of autovaccines in aquaculture systems.

This study aimed to test the efficacy of oil-based commercial and autogenous vaccines against atypical furunculosis and vibriosis in farmed turbot. The impact of these vaccines on health parameters, and fish survival after an experimental challenge was assessed.

\section{Materials and Methods}

The studies presented in this manuscript were approved by the Committee of Bioethics of the Universidade de Santiago de Compostela (USC).

\subsection{Bacterial Strains}

Virulent strains of Aeromonas salmonicida subsp. achromogenes and Vibrio anguillarum originally isolated from diseased turbot during natural epizootics in a Norwegian farm were used for vaccine formulation and challenge tests. The taxonomic position of the strains was confirmed by standard serological and molecular methods [2,21]. Bacteria were grown on tryptic soy agar supplemented with $0.5 \% \mathrm{NaCl}(w / v)(\mathrm{TSA}-1)$ at $18{ }^{\circ} \mathrm{C}$ for $48 \mathrm{~h}$. Stock bacterial cultures were frozen at $-80^{\circ} \mathrm{C}$ in Microbank ${ }^{\mathrm{TM}}$ commercial medium (Pro-Lab Diagnostics, Richmond Hill, ON, Canada).

\subsection{Vaccines}

The paraffin-liquid adjuvanted vaccine Alphaject 3000 (Pharmaq AS, Overhalla, Norway), designed for salmonid fish, and one autogenous vaccine adjuvanted with non-mineral oil, developed in this study for cultured turbot, were comparatively evaluated. The vaccine AlphaJect 3000 (Pharmaq AS, Overhalla, Norway) has been prepared using A. salmoni- 
cida subsp. salmonicida strain AL 2017 and two strains of $V$. anguillarum of the serotypes $\mathrm{O} 1$ (strain AL 112) and O2 $\alpha$ (strain AL 104). The concentration of bacteria included in this vaccine is not specified and a paraffin liquid was used as an adjuvant. The strain R0.16.01.01 of A. salmonicida subsp. achromogenes and the strain of $V$. anguillarum R0.12.04.01 of the serotype $\mathrm{O} 2 \alpha$, both originally isolated from diseased turbot in Norway were used to prepare the autogenous vaccine. To produce this vaccine, the bacteria were pre-cultured in $100 \mathrm{~mL}$ of tryptone soy broth with $1 \% \mathrm{NaCl}(w / v)$ (TSB-1) for $48 \mathrm{~h}$. After that time, $10 \mathrm{~mL}$ of these cultures were inoculated into a $1 \mathrm{~L}$ volume of TSB- 1 and incubated for $48 \mathrm{~h}$ at $20^{\circ} \mathrm{C}$ with shaking at $100 \mathrm{rpm}$. The cultures were inactivated by the addition of formalin to $0.3 \%(v / v)$ with incubation at room temperature for $2 \mathrm{~h}$ and at $4{ }^{\circ} \mathrm{C}$ for $24 \mathrm{~h}$. Inactivation was confirmed by the absence of growth of $1 \mathrm{~mL}$ volumes in TSB-1 and marine broth (MB) after incubation for $72 \mathrm{~h}$ at 20 and $37^{\circ} \mathrm{C}$. To prepare the oil-adjuvanted autogenous bivalent vaccine, pure inactivated cultures of each bacterium were combined and mixed with the non-mineral oil adjuvant Montanide ${ }^{\mathrm{TM}}$ (ISA 763A VG; Seppic, France) in a ratio of 25:75 to obtain a stable fluid emulsion with a final concentration of $5 \times 10^{9}$ cells $/ \mathrm{mL}$ of $V$. anguillarum and $1 \times 10^{10}$ cells $/ \mathrm{mL}$ of $A$. salmonicida susp achromogenes. Sterility was confirmed by spreading the vaccines on TSA-1 and MA plates incubated at 20 and $37^{\circ} \mathrm{C}$ for $72 \mathrm{~h}$.

\subsection{Experimental Fish, Rearing Conditions, and Vaccination Regimes}

A total of 1325 certified disease-free turbot with mean weights of $31 \pm 2 \mathrm{~g}$ were used in the experiments. Sand-filtered seawater was maintained at $16^{\circ} \mathrm{C}$ with an oxygen content of more than $8 \mathrm{mg} / \mathrm{L}$ and a salinity of $32 \mathrm{ppt}$ was used to maintain the fish. Fish were fed a commercial diet during the experiments.

For the vaccination experiments, the fish were distributed into five equal groups (G1, G2, G3, G4, and G5) of 265 individuals each and placed in equal separate tanks. The experimental design and vaccination strategy are outlined in Figure 1. The control group (G1) consisted of 265 fish injected intraperitoneally (i.p.) with $0.1 \mathrm{~mL}$ phosphatebuffered saline (PBS, pH 7.4). Fish in groups 2 (G2) and 3 (G3) were injected i.p. with PBS combined in a 25:75 ratio with the non-mineral oil adjuvant Montanide ${ }^{\mathrm{TM}}$ (ISA 763A VG; Seppic, France) or with Eolane 130 liquid paraffin (Total España, Madrid, Spain). Fish in groups G4 and G5 were injected i.p. with $0.1 \mathrm{~mL}$ of autogenous and commercial vaccine, respectively. Four months later, a group of 80 fish vaccinated with AlphaJect 3000 (Pharmaq AS, Overhalla, Norway) was retrieved from tank G5, boosted by i.p. injection with the same vaccine and dose, and placed in a new tank (G6). Groups of turbot were marked along the fin margins with a visible implantation fluorescent elastomeric dye. The turbots were kept in the farm facilities until they were transported to the Aquarium facilities of the Faculty of Biology of the University of Santiago de Compostela for analysis. On arrival, the fish were acclimatized in 100 or $300 \mathrm{~L}$ tanks at $18 \pm 1{ }^{\circ} \mathrm{C}$ with a seawater flow rate of $5 \mathrm{~mL} / \mathrm{min}$. Prior to any manipulation, fish were anesthetized with methane tricaine sulphonate (MS222, Sigma Aldrich, Madrid, Spain, $60 \mathrm{mg} / \mathrm{L}$ ). During the experiments, the maintenance conditions (feeding, temperature, water flow, oxygenation) were monitored daily for each group of fish to minimize the tank effect.

\subsection{Sampling Procedures and Analysis of Fish Health Status}

Fish were sampled on the initial day and after $45 \mathrm{~d}$ and $160 \mathrm{~d}$ of the treatments for health status, immunological, and histological analyses (Figure 1b). Five to twenty fish were examined from each group at each time point. In each sampling, blood samples were collected from the caudal vessels of anesthetized fish using heparinized syringes for hematocrit determination. Hematocrit was determined by centrifugation technique, and the results reported as a percentage. After blood sampling, all fish were examined for the presence of intraperitoneal adhesions according to the Speilberg index (Ss) [22], assigning the value 0 when no visual adhesion and 6 as the highest value where extensive adhesions in the peritoneal cavity are observed. With this aim, the fishes were sacrificed 
by an overdose of MS $222(180 \mathrm{mg} / \mathrm{L})$ and a standard necropsy was performed and visual appearance of the abdominal cavity (presence of adherence and/or granulomas) of fish was evaluated. Evaluation of side effects was in all cases carried out by the same person to avoid bias due to inter-observer variation. In addition, samples from the heart, liver, and kidney were taken to evaluate histological alterations after vaccine administration. Tissue samples were fixed in $10 \%$ neutral buffered formalin for at least $24 \mathrm{~h}$, embedded in paraffin wax, sectioned at 2-3 $\mu \mathrm{m}$ in thickness, and stained with haematoxylin-eosin (H\&E) for light microscopy observation. Histological features of the examined organs were semi-quantitatively evaluated following this criterion: no lesions (0), low (1), moderate (2), and severe (3). Half scores were used for intermediate situations.

(a)

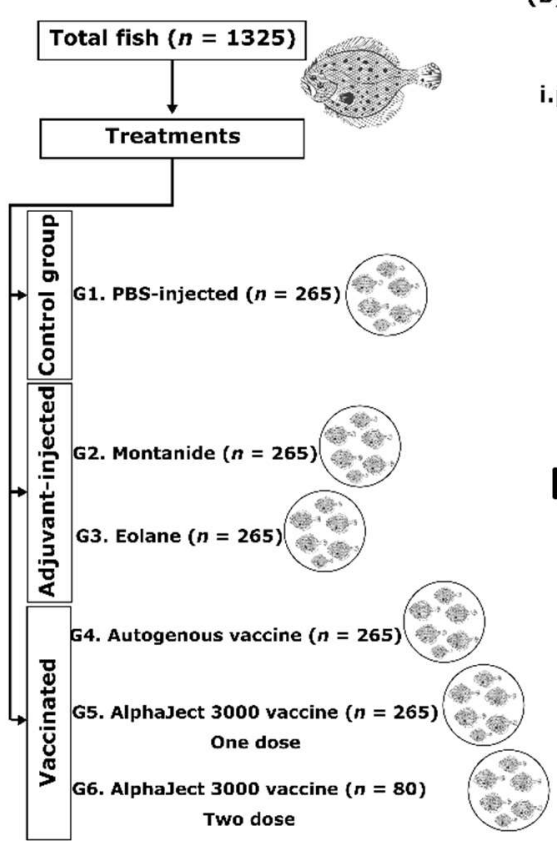

(b)

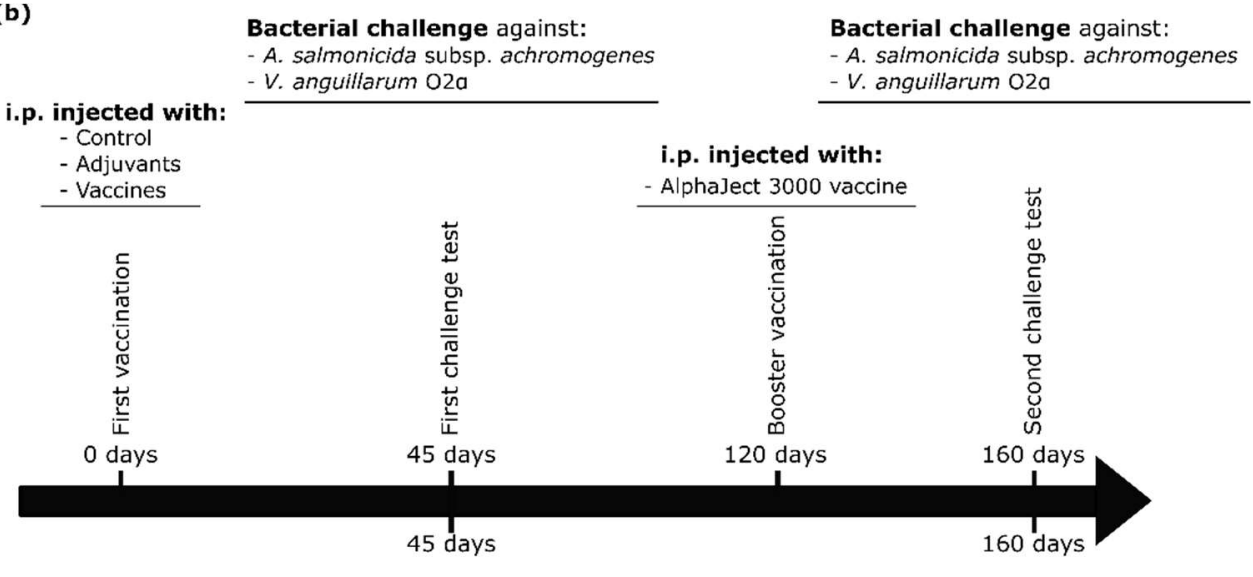

Figure 1. Experimental design (a), vaccination strategy, and sampling procedures (b).

At each sampling point, data of corporal weight (W), visceral weight, and hepatic weight were recovered and used to determine the hepatosomatic index (HSI) and viscerosomatic index (VSI), expressed as a percentage. The HSI index was determined using the formula: HSI $(\%)=100 \times($ liver weight $[\mathrm{g}] /$ whole fish weight [g]). Similarly, the VSI index was calculated using the formula: VSI $(\%)=100 \times($ viscera weight $[\mathrm{g}] /$ whole fish weight $[\mathrm{g}])$.

The respiratory burst activity of the turbot leucocytes was also determined by flow cytometry as previously described [23]. Briefly, the head kidney was aseptically collected and transferred to $5 \mathrm{~mL}$ of serum-free culture minimum essential medium (MEM-Earle, Biochrom, Cambridge, UK) supplemented with $100 \mathrm{IU} / \mathrm{mL}$ penicillin, $100 \mu \mathrm{g} / \mathrm{mL}$ streptomycin (Biochrom), and $10 \mathrm{IU} / \mathrm{mL}$ heparin (Sigma-Aldrich, Madrid, Spain). The cell suspensions were obtained by forcing the tissues through a nylon mesh (mesh size $100 \mu \mathrm{m})$ in cold serum-free MEM. The resulting cell suspensions were placed onto Ficoll-Paque ${ }^{\mathrm{TM}}$ PLUS (Amersham Biosciences, Uppsala, Sweden) and centrifuged at $400 \times g$ for $20 \mathrm{~min}$ at $4{ }^{\circ} \mathrm{C}$ to remove erythrocytes and residues. The leucocyte-rich interphase was collected with a Pasteur pipette, washed twice, counted using the trypan blue exclusion test of cell viability, and adjusted to $10^{6}$ viable cells $/ \mathrm{mL}$ in MEM supplemented with antibiotics and 5\% fetal calf serum (MEM-5) (Biochrom). The respiratory activity of leucocytes was quantified as a measure of intracellular reactive species using dihydrorhodamine 123 (DHR, $10 \mathrm{mM}$, stabilized in DMSO) (Sigma) as an oxidative probe. For measurement of radical production, cells were treated with phorbol 12-myristate-13 acetate (PMA, $0.2 \mu \mathrm{g} / \mathrm{mL}$ in 
dimethyl sulfoxide) (Sigma-Aldrich, Madrid, Spain) or left untreated as controls. Propidium iodine (PI, $0.1 \mu \mathrm{g} / \mathrm{mL}$ ) (Sigma-Aldrich, Madrid, Spain) was added to all samples to gate out $\mathrm{PI}^{+}$cells. The level of intracellular fluorescence was measured in non-stimulated, and PMA stimulated cells. A total number of $1 \times 10^{4}$ events in the cell gate were analyzed. The results were expressed as a stimulation index (SI) which is calculated by dividing the geometric mean fluorescence intensity (GMFI) of treated (PMA) and untreated (Controls) samples. The assays were carried out in triplicate.

Anti-A. salmonicida subsp. achromogenes and $V$. anguillarum antibody titers were determined by standard microtiter agglutination methods. Briefly, the sera were first diluted 1:2 with PBS and then serially diluted ten-fold with the same solution in a 96-well U-shaped microtiter plate with thorough mixing. Then, $10 \mu \mathrm{L}$ of bacterial suspensions $\left(10^{9} \mathrm{CFU} / \mathrm{mL}\right.$; absorbance $620=220$ ) of $V$. anguillarum (serotype $\mathrm{O} 2 \alpha$ strain RO15.11.2) or A. salmonicida subsp. achromogenes (strain RO16.02.01.02) were added to each well and the plate was incubated at $20^{\circ} \mathrm{C}$ for $18 \mathrm{~h}$. Agglutination titers were estimated as the reciprocal of the highest dilution showing agglutination. An auto-agglutination control was performed by mixing bacterial suspensions and sterile PBS instead of antiserum.

All results were subjected to analysis of variance (ANOVA) with the post hoc Tukey HSD and Bonferroni multiple comparison results with a significance level of $p<0.05$.

\subsection{Efficacy of Vaccination}

Vaccine efficacy and duration of immunity were determined by an infectious challenge test and determination of the relative survival percentage (RPS) with a control mortality of 60, according to the recommendations of the European Pharmacopoeia [13]. For the challenge test, fish were infected by i.p. injection with virulent strains of $V$. anguillarum RO15.11.2 and A. salmonicida subsp. achromogenes RO16.02.01.02 after 45 and $160 \mathrm{~d}$ of treatments. Forty-five days after vaccination, turbot in each treatment group were challenged with a suspension of $V$. anguillarum strain RO15.11.2 (50 fish from each group) or A. salmonicida subsp. achromogenes strain RO16.02.01.02 (50 fish from each group). To determine the duration of vaccine-induced immunity, experimental infection with $V$. anguillarum strain RO15.11.2 (30 fish from each group) or with A. salmonicida subsp. achromogenes strain RO16.02.01.02 (30 fish from each group) was carried out $160 \mathrm{~d}$ after vaccination. In addition, fish boosted with AlphaJect 3000 vaccine (Pharmaq AS, Overhalla, Norway), were infected with $V$. anguillarum (30 fish) and A. salmonicida subsp. achromogenes (30 fish) $40 \mathrm{~d}$ after administration of the second dose of vaccine. The number of viable bacterial cells present in the inoculum was determined by seeding $0.1 \mathrm{~mL}$ serial dilutions of the bacterial suspensions on TSA-1 plates and counting the colony-forming units (CFU) produced. Challenged fish were maintained at $18{ }^{\circ} \mathrm{C} \pm 1{ }^{\circ} \mathrm{C}$ and mortalities were recorded daily until at least 60 percent of specific mortality was reached in the control group. The specificity of mortalities was confirmed by seeding samples from internal organs (kidney and spleen) of dead or moribund fish on TSA-1 plates and recovery of inoculated strains in pure culture.

The efficacy of vaccination was evaluated by plotting for both, vaccinated and control group, specific mortality curves against time from challenge. The time corresponding to 60 percent specific mortality in controls was determined by interpolation and the mortality of vaccinated fish (M) was determined at the time corresponding to 60 percent mortality in controls. The RPS was calculated using the following expression [13]: RPS $=(1-\mathrm{M} / 60) \times 100$. The Chi-square test $\left(\chi^{2}\right)$ was also used as a statistical analysis to verify significant differences in survival between vaccinated and control groups after challenge, using a significance level of $p<0.05$.

\section{Results}

\subsection{Macroscopic and Histological Effect of Vaccination}

Side effects of the immunization of turbot with the autogenous and commercial oiladjuvanted vaccines and adjuvants were evaluated by visual and histological analysis (Table 1). The highest degree of damage in the peritoneal cavity, significantly higher than 
the control group $(p<0.005)$, was recorded at $45 \mathrm{~d}$ post-vaccination of turbot with the autogenous vaccine ( $\mathrm{Ss}=5.65 \pm 0.75)$ and the commercial vaccine $(\mathrm{Ss}=4.45 \pm 1.05)$ or injection of the adjuvant Montanide ${ }^{\mathrm{TM}}$ (Ss $=2.60 \pm 0.99$ ). Mild or minor adhesions were detected in fish injected with the adjuvant Eolane $(\mathrm{Sc}=0.68 \pm 0.95)$. Similar results were observed after $160 \mathrm{~d}$ in fish vaccinated with the autogenous vaccine (Ss $=5.50 \pm 0.53$ ) (Table 1$)$, while the lowest $\mathrm{Ss}$ values were observed in fish vaccinated with one $(\mathrm{Ss}=2.50 \pm 1.07)$ or two doses (Ss $=3.88 \pm 0.35)$ of Alphaject 3000 vaccine or fish injected with the mixture PBS:adjuvants (Ss $=0.40 \pm 0.97)$.

Table 1. Macroscopic and microscopic effects of fish after treatments. Results are presented as the mean \pm standard deviation.

\begin{tabular}{|c|c|c|c|c|c|c|c|}
\hline \multirow{3}{*}{ Fish Group } & \multicolumn{2}{|c|}{$\begin{array}{l}\text { Macroscopic Effects } \\
\text { Spielberg Scale (Ss) }\end{array}$} & \multicolumn{5}{|c|}{$\begin{array}{c}\text { Microscopic Effects } \\
\text { Semiquantitative Scale a }\end{array}$} \\
\hline & \multicolumn{2}{|c|}{ Days Post-Treatment } & \multicolumn{5}{|c|}{ Liver } \\
\hline & 45 & 160 & 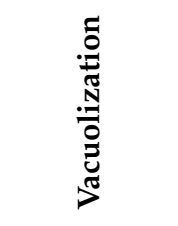 & 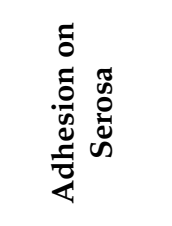 & 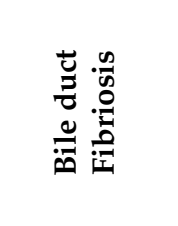 & 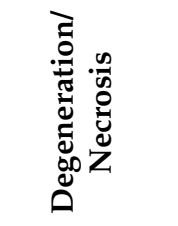 & 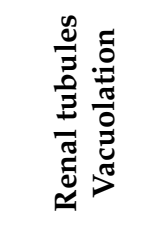 \\
\hline G1 & $0.00 \pm 0.00$ & $0.00 \pm 0.00$ & $2.00 \pm 0.38$ & $0.00 \pm 0.00$ & $1.00 \pm 0.00$ & $1.13 \pm 0.23$ & $0.43 \pm 0.19$ \\
\hline G2 & $2.60 \pm 0.99$ & $0.40 \pm 0.97$ & $1.94 \pm 0.73$ & $0.13 \pm 0.23$ & $1.13 \pm 0.59$ & $0.44 \pm 0.42$ & $0.69 \pm 0.37$ \\
\hline G3 & $0.68 \pm 0.95$ & $0.40 \pm 0.97$ & $1.75 \pm 0.53$ & $0.19 \pm 0.37$ & $1.00 \pm 0.00$ & $0.19 \pm 0.37$ & $0.69 \pm 0.59$ \\
\hline G4 & $5.65 \pm 0.75$ & $5.50 \pm 0.53$ & $1.81 \pm 0.59$ & $0.88 \pm 0.79$ & $1.00 \pm 0.00$ & $0.81 \pm 0.59$ & $0.88 \pm 0.52$ \\
\hline G5 & $4.45 \pm 1.05$ & $2.50 \pm 1.07$ & $2.00 \pm 0.65$ & $0.94 \pm 0.56$ & $1.13 \pm 0.59$ & $0.69 \pm 0.59$ & $1.25 \pm 0.93$ \\
\hline G6 & ND & $3.88 \pm 0.35$ & $1.81 \pm 0.70$ & $0.56 \pm 0.56$ & $1.19 \pm 0.37$ & $0.94 \pm 0.68$ & $0.75 \pm 0.46$ \\
\hline
\end{tabular}

G1, control group; G2, fish injected with Montanide; G3, fish injected with Eolane; G4, fish immunized with the autogenous vaccine; G5

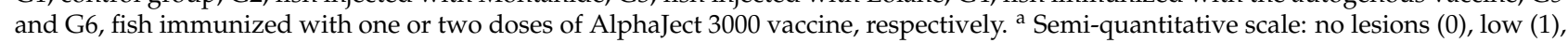
moderate (2), and severe (3). Half scores were used for intermediate situations.

Liver samples showed the most significant histological signs. Histological examination of the liver samples from most groups showed an inflammatory granulomatous reaction associated with the hepatic serosa (Figure 2) consisting of a thick fibrous capsule and empty core granulomas, as well as loose fibrous tissue and a variable amount of mixed inflammatory infiltrate. Only fish injected with PBS showed no granulomatous reaction in this region. Fish injected with the adjuvants (Eolane and Montanide), commercial vaccine, and autovaccine showed focal or multiple granulomatous structures (lesion intensity ranging from $0.13 \pm 0.23$ to $0.94 \pm 0.56$ ), associated with the hepatic serosa and occasionally associated with the exocrine pancreas. In these cases, no lesions or alterations were detected in the liver parenchyma in contact with liver serosa or exocrine pancreas tissue.

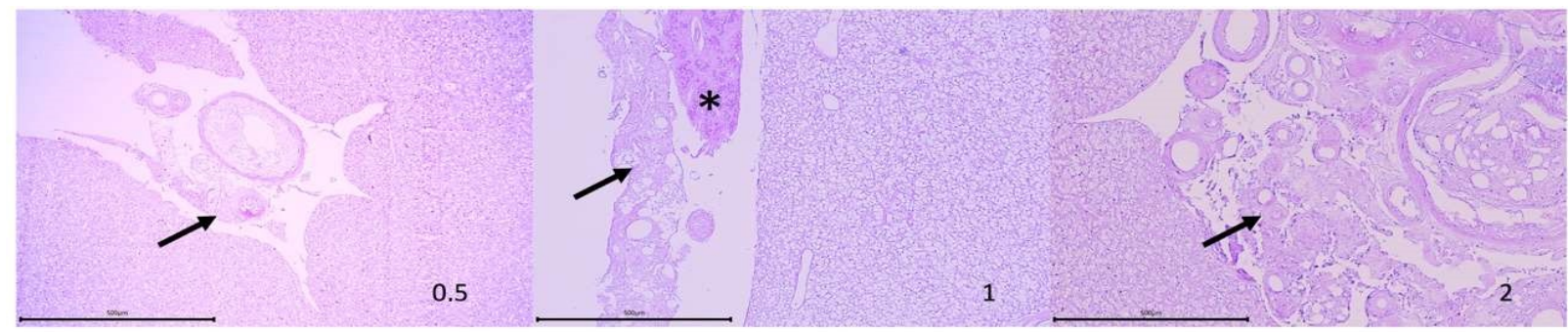

Figure 2. High-power photographs $(40 \times)$ of liver sections showing a variable incidence of perivisceral granulomatous reaction (arrows). Acinar cells of the exocrine pancreas are indicated with an asterisk $\left(^{*}\right)$ and the histological score corresponding to this specific feature is indicated in the lower right corner of each section. Staining: haematoxylin and eosin. Scale bar $100 \mu \mathrm{M}$. 
Intracytoplasmic vacuolation of hepatocytes was also observed, with lesions of varying intensity (values ranging from $1.75 \pm 0.53$ to $2.0 \pm 0.65$ ). These signs are more likely to be associated with differences in food intake than with vaccine injection factors.

Minor, non-specific background histopathological signs were detected in liver parenchyma, kidney, and heart samples, but no other signs were detected that could be clearly related to vaccine or adjuvant injection

\subsection{Evaluation of Physiological Parameters}

The results of the health parameters evaluated are presented in Table 2. After $45 \mathrm{~d}$ post-treatment, the mean body weight of fish ranged from $71.0 \pm 14.0 \mathrm{~g}$ to $88.0 \pm 16.0 \mathrm{~g}$ for vaccinated turbot and from $94.0 \pm 16.0 \mathrm{~g}$ to $106.0 \pm 17.0 \mathrm{~g}$ for fish injected with adjuvants. No significant differences were observed for this parameter with respect to the values found for control fish $(94.0 \pm 17.0 \mathrm{~g})$ (Table 2). The VSI of turbot vaccinated with autogenous $(10.7 \pm 1.8 \%)$ and commercial $(7.6 \pm 0.9 \%)$ vaccines were significantly higher than that of fish injected with Montanide $(6.4 \pm 0.8 \%)$, Eolane $(6.4 \pm 0.9 \%)$ or PBS $(6.0 \pm 1.1 \%)$ (Table 2$)$. Turbot vaccinated with the autogenous vaccine showed significantly lower HSI $(0.7 \pm 1.1 \%)$ $(p<0.05)$ than fish injected with the commercial vaccine $(2.2 \pm 0.3 \%)$, Eolane $(2.0 \pm 0.4 \%)$, Montanide $(2.0 \pm 0.3 \%)$, or PBS $(1.8 \pm 0.3 \%)$ (Table 2$)$. After $160 \mathrm{~d}$ post-immunization, no differences were observed between treatment groups for HSI. The bodyweight of turbot vaccinated with the autogenous vaccine was significantly smaller than that of fish injected with Eolane 130 (339.5 $\pm 73.0 \mathrm{~g})$ or PBS (304.8 $\pm 55.0 \mathrm{~g})$ (Table 2). Differences $(p<0.05)$ were also observed between treatments regarding VSI, which was significantly higher in fish vaccinated with the autogenous vaccine (Table 2).

Table 2. Health parameters of fish after treatments.

\begin{tabular}{|c|c|c|c|c|c|c|c|c|c|c|}
\hline \multirow{2}{*}{$\begin{array}{l}\text { Fish } \\
\text { Group }\end{array}$} & \multicolumn{5}{|c|}{$45 \mathrm{D}$ after Treatment } & \multicolumn{5}{|c|}{$160 \mathrm{D}$ after Treatment } \\
\hline & $\begin{array}{c}\text { Fish } \\
\text { Weight (g) }\end{array}$ & VSI (\%) & HSI (\%) & Hematocrit & SI & $\begin{array}{c}\text { Fish } \\
\text { Weight (g) }\end{array}$ & VSI (\%) & HSI (\%) & Hematocrit & SI \\
\hline G1 & $94.4 \pm 17.0$ & $6.0 \pm 1.1^{b}$ & $1.8 \pm 0.3^{b}$ & $36.6 \pm 13.0$ & $2.7 \pm 1.5$ & $304.8 \pm 55.0^{b}$ & $5.3 \pm 0.2^{b}$ & $1.8 \pm 0.4$ & $26.8 \pm 2.3$ & $1.7 \pm 0.1$ \\
\hline G2 & $94.0 \pm 16.0$ & $6.4 \pm 08^{b}$ & $2.0 \pm 0.3^{b}$ & $32.2 \pm 11.2$ & $1.0 \pm 0.4$ & $285.0 \pm 81.0$ & $5.7 \pm 0.5^{b}$ & $1.6 \pm 0.3$ & $28.8 \pm 4.9$ & $2.0 \pm 0.2$ \\
\hline G3 & $105.7 \pm 17.0$ & $6.4 \pm 0.9^{b}$ & $2.0 \pm 0.4^{b}$ & $42.3 \pm 16.2$ & ND & $339.5 \pm 73.0^{b}$ & $5.6 \pm 0.5^{b}$ & $1.9 \pm 0.4$ & $27.2 \pm 3.1$ & $1.8 \pm 0.3$ \\
\hline G4 & $70.6 \pm 14.0$ & $10.7 \pm 1.8^{a}$ & $0.7 \pm 1.1^{\mathrm{a}}$ & $36.4 \pm 12.6$ & $2.7 \pm 0.6$ & $205.2 \pm 58.0^{\mathrm{a}}$ & $6.8 \pm 0.9^{a}$ & $1.7 \pm 0.2$ & $32.2 \pm 6.2$ & $2.4 \pm 0.6$ \\
\hline G5 & $88.3 \pm 16.0$ & $7.6 \pm 0.9^{a}$ & $2.2 \pm 0.3^{b}$ & $41.0 \pm 6.3$ & $2.1 \pm 0.5$ & $300.6 \pm 42.0$ & $5.6 \pm 0.3^{b}$ & $1.8 \pm 0.2$ & $32.6 \pm 10.5$ & $2.8 \pm 0.3$ \\
\hline G6 & ND & ND & ND & ND & ND & $226.7 \pm 46.0$ & $5.7 \pm 0.5^{b}$ & $1.6 \pm 0.9$ & $32.3 \pm 5.8$ & $2.2 \pm 0.1$ \\
\hline
\end{tabular}

G1, control group; G2, fish injected with Montanide; G3, fish injected with Eolane; G4, fish immunized with the autogenous vaccine; G5 and G6, fish immunized with one or two doses of AlphaJect 3000 vaccine, respectively. VSI, viscerosomatic index $=[$ Visceral weight $(\mathrm{g}) /$ Corporal weight $(\mathrm{g})] \times 100$; HSI, hepatosomatic index $=[$ Liver weight $(\mathrm{g}) /$ Corporal weight $(\mathrm{g})] \times 100$; Hematocrit was determined by centrifugation technique, and the results reported as a percentage. SI: Stimulation index = Geometric mean fluorescence intensity of stimulated leukocytes/Geometric mean fluorescence intensity of unstimulated leukocytes. Data with a different superscript $\left({ }^{a}, b\right)$ in a column were significantly different ANOVA $(p<0.05)$.

After 45- and 160-d post-treatment, respiratory burst activity (SI) of kidney leukocytes and hematocrit values of turbot vaccinated (groups G4, G5, and G6) or injected with adjuvants (groups G2 and G3) showed no significant differences with respect to those obtained with the control group (G1) (Table 2).

The specific immune response in turbot immunized with autogenous and AlphaJect 3000 vaccines was assessed by measuring serum agglutinating antibody titers at 45- and 160-d post-vaccination, using inactivated whole bacterial cells of $A$. salmonicida subsp achromogenes and $V$. anguillarum as antigens. Only sera from fish immunized with the autogenous and the commercial vaccines displayed specific agglutination with the antigens of both pathogens (Table 3$)$. Significative $(p<0.05)$ higher values of agglutinating antibody titer against $A$. salmonicida subsp salmonicida were only recorded after $45 \mathrm{~d}$ of immunization of fish with the autogenous vaccine. Similar titer values against $V$. anguillarum antigens were observed in fish immunized with the autogenous and commercial vaccines $45 \mathrm{~d}$ post-vaccination. After $160 \mathrm{~d}$ post-vaccination, only fish vaccinated with a single dose of the autogenous vaccine or two doses of the commercial vaccine AlphaJect 3000 maintained notable antibodies titers against Aeromonas and Vibrio antigens. 
Table 3. Results of the agglutination assay using the serum of turbot injected with PBS, eolane, montanide, autogenous (one dose), and commercial vaccines (one and two doses).

\begin{tabular}{|c|c|c|c|c|c|c|c|c|c|c|c|}
\hline \multirow{3}{*}{ Antigens } & \multicolumn{11}{|c|}{ Fish Groups } \\
\hline & \multicolumn{2}{|c|}{ G1 } & \multicolumn{2}{|c|}{ G2 } & \multicolumn{2}{|c|}{ G3 } & \multicolumn{2}{|c|}{ G4 } & \multicolumn{2}{|c|}{ G5 } & \multirow{2}{*}{\begin{tabular}{|c|} 
G6 \\
$160 d$
\end{tabular}} \\
\hline & $45 d$ & $160 d$ & $45 d$ & $160 d$ & $45 d$ & $160 d$ & $45 d$ & $160 d$ & $45 d$ & $160 d$ & \\
\hline $\begin{array}{c}\text { A. salmonicida } \\
\text { subsp. } \\
\text { achromogenes }\end{array}$ & $<2^{b}$ & $<2^{b}$ & $<2^{b}$ & $<2^{b}$ & $<2^{b}$ & $<2^{b}$ & $1468 \pm 878^{a}$ & $200 \pm 0^{b}$ & $174 \pm 68^{\mathrm{b}}$ & $12 \pm 10^{b}$ & $200 \pm 0^{b}$ \\
\hline $\begin{array}{l}\text { V. anguillarum } \\
\mathrm{O} 2 \alpha\end{array}$ & $2 \pm 0^{\mathrm{b}}$ & $<2^{\mathrm{b}}$ & $<2^{b}$ & $<2^{\mathrm{b}}$ & $<2^{b}$ & $<2^{\mathrm{b}}$ & $637 \pm 934^{\mathrm{b}}$ & $140 \pm 104^{b}$ & $406 \pm 708^{b}$ & $16 \pm 9^{b}$ & $650 \pm 900^{b}$ \\
\hline
\end{tabular}

G1, control group; G2, fish injected with Montanide; G3, fish injected with Eolane; G4, fish immunized with the autogenous vaccine; G5 and G6, fish immunized with one or two doses of AlphaJect 3000 vaccine, respectively. $45 \mathrm{~d}$ and $160 \mathrm{~d}$, 45 and $160 \mathrm{~d}$ post-treatment; Results expressed as mean \pm standard deviation of agglutination titters using samples of 6 fish per treatment. Data with a different superscript $(\mathrm{a}, \mathrm{b})$ in a column were significantly different ANOVA $(p<0.05)$.

\subsection{Efficacy of Vaccines}

The results of the infective challenge $45 \mathrm{~d}$ post-vaccination showed that turbot i.p vaccinated with the oil-based autogenous (group G4) and AlphaJect 3000 (G5 and G6) vaccines were fully protected (RPS = 100; Table 4) following i.p. challenge with V. anguillarum. However, only the autogenous vaccine (G4) conferred high levels of protection of turbot against $A$. salmonicida subsp. achromogenes (RPS $=83 \%$ ). One-hundred- and sixty-days post-vaccination, moderate protection against $V$. anguillarum was obtained for both fish immunized with one (G5) or two (G6) doses of AlphaJect 3000 vaccine (RPS $=52$ to $60 \%$ ), and fish immunized with a single dose of the autogenous (G4) vaccine (RPS $=67 \%$ ). In contrast, increased levels of protection after challenge with A. salmonicida subsp. achromogenes were observed in turbot vaccinated with one (G5, RPS $=77 \%)$ or two doses of AlphaJect $3000(\mathrm{G} 6, \mathrm{RPS}=100 \%)$ or a single dose of the autogenous vaccines $(\mathrm{G} 4, \mathrm{RPS}=100 \%) \cdot \chi^{2}$ statistical analyses showed significant differences $(p<0.05)$ between the final mortalities of the vaccinated groups (challenged after 45- and 160-d post-immunization) and the respective control groups.

Table 4. Efficacy bivalent vaccines and vaccination procedures carried out in turbot under laboratory conditions.

\begin{tabular}{|c|c|c|c|c|c|}
\hline \multirow{2}{*}{ Fish Group } & \multicolumn{2}{|c|}{ Vaccination Procedure } & \multirow{2}{*}{$\begin{array}{l}\text { Infectious Dose } \\
\text { Cells/Fish }\end{array}$} & \multirow{2}{*}{ \%Mortality } & \multirow{2}{*}{$\mathrm{RPS}_{60}$} \\
\hline & Primary Dose & Booster Dose & & & \\
\hline \multicolumn{6}{|c|}{ Protection against $V$. anguillarum $45 \mathrm{~d}$ Postvaccination } \\
\hline G1 & i.p. injection & & \multirow{5}{*}{$1 \times 10^{9}$} & $60^{a}$ & \\
\hline G2 & i.p. injection & & & $37^{b}$ & 38 \\
\hline G3 & i.p. injection & & & $35^{b}$ & 42 \\
\hline G4 & i.p. injection & & & $0^{b}$ & 100 \\
\hline G5 & i.p. injection & & & $0^{b}$ & 100 \\
\hline \multicolumn{6}{|c|}{ Protection against $A$. salmonicida subsp. achromogenes $45 \mathrm{~d}$ postvaccination } \\
\hline G1 & i.p. injection & & \multirow{5}{*}{$9.9 \times 10^{8}$} & $60^{a}$ & \\
\hline G2 & i.p. injection & & & $4^{b}$ & 93 \\
\hline G3 & i.p. injection & & & $4^{b}$ & 93 \\
\hline G4 & i.p. injection & & & $10^{b}$ & 83 \\
\hline G5 & i.p. injection & & & $30^{b}$ & 50 \\
\hline \multicolumn{6}{|c|}{ Protection against $V$. anguillarum 160 d postvaccination } \\
\hline G1 & i.p. injection & & \multirow{6}{*}{$6.6 \times 10^{10}$} & $60^{a}$ & \\
\hline G2 & i.p. injection & & & 57 & 5 \\
\hline G3 & i.p. injection & & & 56 & 7 \\
\hline G4 & i.p. injection & & & $29^{b}$ & 52 \\
\hline G5 & i.p. injection & & & $20^{b}$ & 67 \\
\hline G6 & i.p. injection & i.p. injection & & $24^{b}$ & 60 \\
\hline
\end{tabular}


Table 4. Cont.

\begin{tabular}{|c|c|c|c|c|c|}
\hline \multirow{2}{*}{ Fish Group } & \multicolumn{2}{|c|}{ Vaccination Procedure } & \multirow{2}{*}{$\begin{array}{l}\text { Infectious Dose } \\
\text { Cells/Fish }\end{array}$} & \multirow{2}{*}{ \%Mortality } & \multirow{2}{*}{$\mathrm{RPS}_{60}$} \\
\hline & Primary Dose & Booster Dose & & & \\
\hline \multicolumn{6}{|c|}{ Protection against $A$. salmonicida subsp. achromogenes $160 \mathrm{~d}$ postvaccination } \\
\hline G1 & i.p. injection & & \multirow{6}{*}{$1.4 \times 10^{10}$} & $60^{a}$ & \\
\hline G2 & i.p. injection & & & 78 & 0 \\
\hline G3 & i.p. injection & & & $27^{b}$ & 55 \\
\hline G4 & i.p. injection & & & $0^{b}$ & 100 \\
\hline G5 & i.p. injection & & & $14^{\mathrm{b}}$ & 77 \\
\hline G6 & i.p. injection & i.p. injection & & $0^{\mathrm{b}}$ & 100 \\
\hline
\end{tabular}

G1, control group; G2, fish injected with Montanide; G3, fish injected with Eolane; G4, fish immunized with autogenous vaccines; G5 and G6, fish immunized with one or two doses of AlphaJect 3000 vaccine, respectively. RPS60, Relative survival rate $60 \%=(1-\mathrm{M} / 60) \times 100$ (European Pharmacopoeia 7.0, 2010). Calculation based on the percentage of specific mortality in the vaccinated group (M), obtained by interpolation at the time when 60 percent of the specific mortality in the control group is reached. Data with a different superscript $\left({ }^{a}, b\right)$ in $a$ column were significantly different $\chi^{2}(p<0.05)$.

The specific antibody response elicited by the different vaccines correlates with the degree of protection offered by each of them. However, vaccination had no significant effect on the respiratory burst activity of kidney leucocytes or on the hematocrit levels of fish blood.

The influence of the i.p. injection of adjuvants Montanide ${ }^{\mathrm{TM}}$ ISA 763A VG and Eolane 130 on survival of fish after challenge with $V$. anguillarum and A. salmonicida subsp. achromogenes was also evaluated (Table 4). Fish injected with Montanide ${ }^{\mathrm{TM}}$ (ISA 763A VG) showed low protection values after challenge with $V$. anguillarum $(\mathrm{G} 2, \mathrm{RPS}=38 \%)$. Similar results were obtained for fish injected with the adjuvant Eolane 130 (G3) (Table 4). Statistical analysis showed significant differences $(p<0.05)$ between the final cumulative mortalities achieved in the groups injected with adjuvants (G2 and G3) and the control groups injected with PBS (G1) after $45 \mathrm{~d}$ post-vaccination. In contrast, fish injected with both adjuvants showed high protection levels against $A$. salmonicida subsp. achromogenes. In most cases, these protection levels (RPS) decrease after $160 \mathrm{~d}$ of the injection of the adjuvants (RPS values ranging from $0 \%$ to $55 \%$ for $A$. salmonicida subp. achromogenes and $5 \%$ to $7 \%$ for V. anguillarum; Table 4).

\section{Discussion}

Vibriosis and atypical furunculosis are two of the bacterial diseases causing mortalities in intensively farmed turbot. Although several commercial vaccines exist to prevent vibriosis and furunculosis in fish, most of these vaccines are tested on salmonids and/or contain antigens against $A$. salmonicida subsp. salmonicida, which is responsible for typical furunculosis. Therefore, this study aimed to test the efficacy of oil-based commercial and autogenous vaccines against atypical furunculosis and vibriosis in farmed turbot. The impact of these vaccines on health parameters, and fish survival after the experimental challenge was assessed.

Vaccine efficacy can be improved by using adjuvants together with the selected antigens. Among adjuvanted vaccines, formulations with mineral oil adjuvants have been associated with side effects, such as growth impairment [24-26], pigmentation, inflammation, and granulomatous lesion formation $[25,27,28]$ and fibrous adhesions in internal organs [26,28-30]. In the present study, severe side effects (inflammation, granulomas, and organ adhesion) were observed with turbot immunized with the autogenous vaccines, and lower effects with the commercial vaccine and the adjuvant Montanide. These alterations could be caused by the deposition of adjuvants on or between organs, which infiltrate, forming a vaccine cell mass that facilitates the formation of adhesions [31-33]. One hundredand sixty-days post-treatment, significantly elevated Ss values were still observed in fish immunized with the autogenous and commercial vaccine (one and two doses), but not in fish treated with the adjuvant Montanide ${ }^{\mathrm{TM}}$ (ISA 763A VG; Seppic, France) alone. These 
results seem to indicate that these side effects are caused by interactions of the antigens and the oil emulsion adjuvant [24,34,35]. In contrast, fish injected with the adjuvant Eolane showed only mild or minor adhesions. These results suggest that Eolane is a well-tolerated oily adjuvant for turbot that could be considered in future vaccine development.

Body indexes help to determine the health status of fish by providing specific information related to the function of the selected organ [36]. Among the growth performance parameters analyzed, differences were found for fish weight and HSI, significantly reduced in fish vaccinated with the Montanide-adjuvanted autogenous vaccine. There are divergent opinions on the role of oily adjuvants for observed growth reduction in vaccinated fish. While some authors [37] consider that interacting antigen-adjuvant rather than the adjuvant components themselves are responsible for reduced growth in vaccinated fish, others have postulated that adhesions and lesions caused by vaccination lead to a reduction in feed uptake and growth [38,39].

Microscopically, liver lesions were observed in fish injected with oil-based adjuvants and adjuvanted vaccines, predominantly mild to moderate necrosis and granulomatous structures attached to the serosa and, occasionally, to the exocrine pancreas. Histological alterations such as local necrosis or granulomatous lesions in hepatic tissue are consistent with previous observations in turbot and cod injected with oil-adjuvanted vaccines $[31,35]$. Intracytoplasmic vacuolation of hepatocytes and non-specific background histopathological signs were detected in the liver parenchyma, kidney, and heart samples. However, these alterations can be commonly observed in healthy fish and should not be considered as a relevant alteration associated with the treatments applied to the fish in the present study.

The hematocrit values have been considered as a simple and non-specific indicator of fish health over the years [40-43], moreover, this indicator has resulted in an informative index in cultured fish [44]. In the current study, no significant differences were observed between the hematocrit value in the treated fish groups. The respiratory activity of macrophages has also been evaluated because the cellular response plays an important role in host defense mechanisms, demonstrated by their action in coagulation and inflammation processes, and phagocytic activity in infectious processes [45]. However, in this study, no significant differences were found between the stimulation index between vaccinated and control fish after 45 and 160-d post-vaccination.

The efficacy and duration of immunity of the vaccines were tested by an infectious challenge test with $V$. anguillarum and A. salmonicida subsp. achromogenes and determination of RPS. After $45 \mathrm{~d}$ post-treatment, the commercial and autogenous vaccines induced complete protection against $V$. anguillarum $(\mathrm{RPS}=100 \%$ ). However, only the bivalent autogenous vaccine, which included antigens of a strain of A. salmonicida subsp achromogenes isolated from turbot, conferred high levels of protection (RPS $=83 \%$ ) against this pathogen after administration of a single dose. A likely explanation for the high levels of protection conferred by the autogenous vaccine against both pathogens could be the use of specific antigens in the appropriate dose, which are important in the stimulation of the immune system of this fish species. Similar results were found comparing vaccines against typical and atypical furunculosis [11,46]. The duration of immunization of the vaccines was tested by infectious challenge test after $160 \mathrm{~d}$ post-treatment. Only fish vaccinated with a single dose of autogenous vaccine retained high levels of protection against $V$. anguillarum and A. salmonicida subsp. achromogenes. The possibility of using bivalent vaccines in a single dose would reduce stress to the fish and reduce costs for the farmers. Therefore, the high levels of protection observed using the autogenous vaccine could represent a significant improvement for both fish health and the farming economy.

\section{Conclusions}

The oil-based autogenous bivalent vaccine developed in this study, conferred high levels of long-term protection against atypical furunculosis and vibriosis after administration of a single dose in turbot, at the cost of high side effects in the fish. Therefore, further studies should be focused on autovaccines and the evaluation of other adjuvants 
that improve protection with reduced or no side effects. In this sense, the liquid paraffin Eolane 130 evaluated in this study, which is a well-tolerated adjuvant for turbot, is a promising candidate that could be considered in future vaccine development.

Author Contributions: All authors contributed to the study conception and design. Material preparation, data collection and analysis were performed by Y.T.-C., A.G., O.G.-B., R.S., A.R. and Y.S. The first draft of the manuscript was written by Y.T.-C. and Y.S., and all authors commented on previous versions of the manuscript. All authors have read and agreed to the published version of the manuscript.

Funding: This work was partially supported by the Proof-of-Concept Program "Acelerador de Transferencia" from the Universidade of Santiago de Compostela (Spain).

Institutional Review Board Statement: The study was conducted according to the guidelines approved by the Committee of Bioethics of the Universidade de Santiago de Compostela (USC).

Informed Consent Statement: Not applicable.

Data Availability Statement: The dataset used and/or analyzed during the current study are available from the corresponding author on reasonable request.

Acknowledgments: This work was partially supported by the Proof-of-Concept Program "Acelerador de Transferencia" from the Universidade of Santiago de Compostela (Spain). Y.T.C. was supported by a grant from the Universidade of Santiago de Compostela under the program "Acelerador de Transferencia".

Conflicts of Interest: The authors declare no conflict of interest.

\section{References}

1. FAO. El Estado Mundial de la Pesca y la Acuicultura 2018. Cumplir los Objetivos de Desarrollo Sostenible; FAO: Rome, Italy, 2018; ISBN 978-92-5-130688-8.

2. Austin, B.; Austin, D.A. Bacterial Fish Pathogens, 6th ed.; Springer: Chichester, UK, 2016; ISBN 978-3-319-32673-3.

3. Novotny, A.J. Vibriosis and furunculosis in marine cultured salmon in Puget Sound, Washington. Mar. Fish. Rev. 1978, $40,52-55$.

4. García Carballas, C.M. Respuesta Inmune en Rodaballo (Psetta máxima) y Lenguado (Solea sp). Efecto de la Vacunación. Ph.D. Thesis, Universidade de Santiago de Compostela, Santiago, Spain, 2018.

5. Wiklund, T.; Dalsgaard, I. Occurrence, and significance of atypical Aeromonas salmonicida in non-salmonid and salmonid fish species: A review. Dis. Aquat. Organ. 1998, 32, 49-69. [CrossRef]

6. Toranzo, A.E.; Magariños, B.; Romalde, J.L. A review of the main bacterial fish diseases in mariculture systems. Aquaculture 2005, 246, 37-61. [CrossRef]

7. Santos, Y.; Pazos, F.; Bandin, I.; Toranzo, A.E. Analysis of antigens present in the extracellular products and cell surface of Vibrio anguillarum serotypes O1, O2, and O3. Appl. Environ. Microbiol. 1995, 61, 2493-2498. [CrossRef] [PubMed]

8. Bondad-Reantaso, M.G.; Arthur, J.R.; Subasinghe, R.P. Improving biosecurity through prudent and responsible use of veterinary medicines in aquatic food production. In FAO Fisheries and Aquaculture Technical Paper; No. 547; FAO: Rome, Italy, 2012; ISBN 2070-7010.

9. Håstein, T.; Gudding, R.; Evensen, O. Bacterial vaccines for fish-An update of the current situation worldwide. Dev. Biol. 2005, $121,55-74$.

10. Björnsdóttir, B.; Gudmundsdóttir, S.; Bambir, S.H.; Gudmundsdóttir, B.K. Experimental infection of turbot, Scophthalmus maximus (L.), by Aeromonas salmonicida subsp. achromogenes and evaluation of cross protection induced by a furunculosis vaccine. J. Fish Dis. 2005, 28, 181-188. [CrossRef]

11. Santos, Y.; García-Marquez, S.; Pereira, P.G.; Pazos, F.; Riaza, A.; Silva, R.; El Morabit, A.; Ubeira, F.M. Efficacy of furunculosis vaccines in turbot, Scophthalmus maximus (L.): Evaluation of immersion, oral and injection delivery. J. Fish Dis. 2005, 28, 165-172. [CrossRef] [PubMed]

12. Toranzo, A.E.; Santos, Y.; Barja, J.L. Immunization with bacterial antigens: Vibrio infections. Dev. Biol. Stand. 1997, 90, 90-105.

13. European pharmacopoeia. Vibriosis (cold-water) vaccine (inactivated) for salmonids. In European pharmacopoeia; Council of Europe, European Directorate for the Quality of Medicines and Healthcare: Strasbourg, France, 2010; pp. 2-3.

14. Mikkelsen, H.; Lund, V.; Larsen, R.; Seppola, M. Vibriosis vaccines based on various sero-subgroups of Vibrio anguillarum O2 induce specific protection in Atlantic cod (Gadus morhua L.) juveniles. Fish Shellfish Immunol. 2011, 30, 330-339. [CrossRef]

15. Liu, X.; Jiao, C.; Ma, Y.; Wang, Q.; Zhang, Y. A live attenuated Vibrio anguillarum vaccine induces efficient immunoprotection in Tiger puffer (Takifugu rubripes). Vaccine 2018, 36, 1460-1466. [CrossRef]

16. Vigneulle, M.; Laurencin, F.B. Uptake of Vibrio anguillarum bacterin in the posterior intestine of rainbow trout Oncorhynchus mykiss, sea bass Dicentrarchus labrax and turbot or anal intubation. Dis. Aquat. Organ. 1991, 11, 85-92. [CrossRef] 
17. Norqvist, A.; Hagström, A.; Wolf-Watz, H. Protection of rainbow trout against vibriosis and furunculosis by the use of attenuated strains of Vibrio anguillarum. Appl. Environ. Microbiol. 1989, 55, 1400-1405. [CrossRef] [PubMed]

18. Villumsen, K.R.; Koppang, E.O.; Christensen, D.; Bojesen, A.M. Alternatives to mineral oil adjuvants in vaccines against Aeromonas salmonicida subsp. salmonicida in rainbow trout offer reductions in adverse effects. Sci. Rep. 2017, 7, 5930. [CrossRef]

19. Bao, P.; Sun, X.; Liu, Q.; Zhang, Y.; Liu, X. Synergistic effect of a combined live Vibrio anguillarum and Edwardsiella piscicida vaccine in turbot. Fish Shellfish Immunol. 2019, 88, 84-90. [CrossRef] [PubMed]

20. Ellis, A.E. Immunization with bacterial antigens: Furunculosis. Dev. Biol. Stand. 1997, 90, 107-116. [PubMed]

21. Buller, N. Bacteria and Fungi from Fish and Other Aquatic Animals, 2nd ed.; CABI Publishing: Wallingford, UK, 2014; ISBN 0851997384.

22. Midtlyng, P.J.; Lillehaug, A. Growth of Atlantic salmon Salmo salar after intraperitoneal administration of vaccines containing adjuvants. Dis. Aquat. Organ. 1998, 32, 91-97. [CrossRef]

23. Morabit, A.; Carballas, C.G.; Seoane, R.; Riaza, A.; Santos, Y. Flow cytometric study of phagocytic and oxidative burst activities of turbot head-kidney leucocytes in response to Aeromonas salmonicida subspecies salmonicida and Tenacibacterium maritimum. In Recent Research Developments in Microbiology; Panadalai, S.G., Ed.; Research Signpost: New York, NY, USA, 2006; Volume 10, ISBN 81-308-0022-5.

24. Melingen, G.O.; Wergeland, H.I. Physiological effects of an oil-adjuvanted vaccine on out-of-season Atlantic salmon (Salmo salar L.) smolt. Aquaculture 2002, 214, 397-409. [CrossRef]

25. Durbin, A.P.; Cho, C.J.; Elkins, W.R.; Wyatt, L.S.; Moss, B.; Murphy, B.R. Comparison of the immunogenicity and efficacy of a replication-defective vaccinia virus expressing antigens of human parainfiuenza virus type 3 (HPIV3) with those of a live attenuated HPIV3 vaccine candidate in rhesus monkeys passively immunized with PIV3 antibodies. J. Infect. Dis. 1999, 179, 1345-1351. [CrossRef]

26. Menanteau-Ledouble, S.; Kumar, G.; Saleh, M.; El-Matbouli, M. Aeromonas salmonicida: Updates on an old acquaintance. Dis. Aquat. Organ. 2016, 120, 49-68. [CrossRef]

27. Midtlyng, P.J. Vaccinated fish welfare: Protection versus side-effects. Dev. Biol. Stand. 1997, 90, 371-379.

28. Koppang, E.O.; Haugarvoll, E.; Hordvik, I.; Aune, L.; Poppe, T.T. Vaccine-associated granulomatous inflammation and melanin accumulation in Atlantic salmon, Salmo salar L., white muscle. J. Fish Dis. 2005, 28, 13-22. [CrossRef]

29. Berg, A.; Rødseth, O.M.; Hansen, T. Fish size at vaccination influence the development of side-effects in Atlantic salmon (Salmo salar L.). Aquaculture 2007, 265, 9-15. [CrossRef]

30. Coscelli, G.A.; Bermúdez, R.; Losada, A.P.; Santos, Y.; Quiroga, M.I. Vaccination against Aeromonas salmonicida in turbot (Scophthalmus maximus L.): Study of the efficacy, morphological changes, and antigen distribution. Aquaculture 2015, 445, 22-32. [CrossRef]

31. Noia, M.; Domínguez, B.; Leiro, J.; Blanco-Méndez, J.; Luzardo-Álvarez, A.; Lamas, J. Inflammatory responses and side effects generated by several adjuvant-containing vaccines in turbot. Fish Shellfish Immunol. 2014, 38, 244-254. [CrossRef]

32. Aucouturier, J.; Dupuis, L.; Ganne, V. Adjuvants designed for veterinary and human vaccines. Vaccine 2001, 19, 2666-2672. [CrossRef]

33. Jaafar, R.M.; Chettri, J.K.; Dalsgaard, I.; Al-Jubury, A.; Kania, P.W.; Skov, J.; Buchmann, K. Effects of adjuvant Montanide ${ }^{\mathrm{TM}}$ ISA 763 A VG in rainbow trout injection vaccinated against Yersinia ruckeri. Fish Shellfish Immunol. 2015, 47, 797-806. [CrossRef] [PubMed]

34. Romstad, A.B.; Reitan, L.J.; Midtlyng, P.; Gravningen, K.; Evensen, Ø. Antibody responses correlate with antigen dose and in vivo protection for oil-adjuvanted, experimental furunculosis (Aeromonas salmonicida subsp. salmonicida) vaccines in Atlantic salmon (Salmo salar L.) and can be used for batch potency testing of vaccines. Vaccine 2013, 31, 791-796. [CrossRef] [PubMed]

35. Mutoloki, S.; Alexandersen, S.; Gravningen, K.; Evensen, $\varnothing$. Time-course study of injection site inflammatory reactions following intraperitoneal injection of Atlantic cod (Gadus morhua L.) with oil-adjuvanted vaccines. Fish Shellfish Immunol. 2008, 24, 386-393. [CrossRef] [PubMed]

36. Montenegro, D.; González, M.T. Evaluation of somatic indexes, hematology, and liver histopathology of the fish Labrisomus philippii from San Jorge Bay, northern Chile, as associated with environmental stress. Rev. Biol. Mar. Oceanogr. 2012, 47, 99-107. [CrossRef]

37. Rønsholdt, B.; McLean, E. The effect of vaccination and vaccine components upon short-term growth and feed conversion efficiency in rainbow trout. Aquaculture 1999, 174, 213-221. [CrossRef]

38. Berg, A.; Rodseth, O.M.; Tangerás, A.; Hansen, T. Time of vaccination influences development of adhesion, growth, and spinal deformities in Atlantic salmon Salmo salar. Dis. Aquat. Org. 2006, 69, 239-248. [CrossRef]

39. Li, J.; Tang, L.; Li, S.; Li, G.; Mo, Z. The efficacy and side-effects of oil-based adjuvants emulsified Vibrio anguillarum bivalent inactivated vaccine in turbot (Scophthalmus maximus) under production mode. Aquaculture 2020, 524, 735259. [CrossRef]

40. Fazio, F. Fish hematology analysis as an important tool of aquaculture: A review. Aquaculture 2019, 500, 237-242. [CrossRef]

41. Satheeshkumar, P.; Ananthan, G.; Kumar, D.S.; Jagadeesan, L. Haematology and biochemical parameters of different feeding behaviour of teleost fishes from Vellar estuary, India. Comp. Clin. Path. 2012, 21, 1187-1191. [CrossRef]

42. Ivanc, A.; Haskovic, E.; Jeremic, S.; Dekic, R. Hematological evaluation of welfare and health of fish. Prax. Vet. 2016, 53, 191-202.

43. Cazenave, J.; Wunderlin, D.A.; Hued, A.C.; Bistoni, M.D.L.Á. Haematological parameters in a neotropical fish, Corydoras paleatus (Jenyns, 1842) (Pisces, Callichthyidae), captured from pristine and polluted water. Hydrobiologia 2005, 537, 25-33. [CrossRef] 
44. Kim, J.H.; Jeong, M.H.; Jun, J.C.; Kim, T.I. Changes in hematological, biochemical, and non-specific immune parameters of olive flounder, Paralichthys olivaceus, following starvation. Asian Australas. J. Anim. Sci. 2014, 27, 1360-1367. [CrossRef]

45. Faílde, L.D.; Losada, A.P.; Bermúdez, R.; Santos, Y.; Quiroga, M.I. Tenacibaculum maritimum infection: Pathology and immunohistochemistry in experimentally challenged turbot (Psetta maxima L.). Microb. Pathog. 2013, 65, 82-88. [CrossRef]

46. Gudmundsdóttir, B.K.; Björnsdóttir, B. Vaccination against atypical furunculosis and winter ulcer disease of fish. Vaccine 2007, 25, 5512-5523. [CrossRef] 